\title{
Soft Skills for Enhancing Employability
}

\author{
Dr. B.Bala Nagendra Prasad* \\ Assistant Professor of English, Department of Humanities and Sciences, Annamacharya Institute of Technology \\ and Sciences, Rajampet, Andhra Pradesh, India
}

*Corresponding Author: Dr. B.Bala Nagendra Prasad, Assistant Professor of English, Department of Humanities and Sciences, Annamacharya Institute of Technology and Sciences, Rajampet, Andhra Pradesh, India.

\begin{abstract}
Employability is defined as a set of achievements, understanding and personal attributes that make individuals gain employment and be successful in their chosen occupations. Interestingly, employability is not simply about getting a job. Also, simply by securing technical skills, employment does not become automatic. While technical skills are very important for success in business, there are other non-technical skills which hold equal importance in the employability factor of an individual. These non-technical skills are called soft skills. Of late, the development and possession of these soft skills is also being seen as the potential for employability of an individual. Obviously, the theme of employability is changing. Creating lifelong employment capabilities in individuals is a role found to be played by the enhancement of soft skills so much so that the terms, soft skills and employability, are used interchangeably. It is also seriously realized that the organizational effectiveness and sustainability does not solely depend on 'technical skills' but to great extent on 'soft skills'. This paper attempts to identify such skill sets that influence employability from employer's perspective. The intention of the author is also to throw light on the change and the nature of employability skills and wider perspectives of employability in the $21^{\text {st }}$ century.
\end{abstract}

Keywords: Employability, employer, soft skills, technical skills

\section{INTRODUCTION}

Skills are positive factors for the growth of individuals, for employers, and for nations. Individuals' skills influence their chances of getting and retaining a job that is fulfilling and financially rewarding. Employers need skilled people if their organizations are to be productive, innovative and profitable, surviving and prospering in an increasingly competitive world. A country's skill base is a critical national asset, contributing to economic achievement, standards of living and, through its impact on individual well being, social cohesion.

While technical skills are very important for success in business, there are other non-technical skills which hold equal importance in the employability factor of an individual. These non-technical skills are generally called soft skills. Nowadays, soft skills are not only used to enter the workplace but also sustain oneself in the workplace.

Soft skills help an individual to develop, to think to analyze, to solve problems and to communicate. The relationship between soft skills and the employability quotient of an individual is often discussed in the industry. The term "Soft Skill" is being used interchangeably with the term "Employability" in the labor market. This indicates that in order to increase the chances of being employed continuously throughout life, an individual must, in addition to technical skills, necessarily possess soft skills.

\section{EMPLOYABILITY}

The term employability has multiple definitions. The University of Newcastle has defined employability as a capacity to move self-sufficiently into and within the labor market, to fulfill one's potential through sustainable employment, so imposing the responsibility of depending on oneself to move into and forward on the individual. It is elsewhere defined as "a set of achievements, understanding and personal attributes that make individuals more likely to gain employment and be successful in their chosen occupations". These definitions are, however, hasty in clarifying that employability is not simply about getting job. 


\section{THE EMPLOYER'S STANDPOINT}

It has been found that employers want recruits who are going to be effective in a constantly changing world. In other words, they want people who not only can cope with change but also grow in it. They also want people who can apply their skills to a range of activities from the known to the unknown and to adapt to new approaches without resistance. For all this, employers demand that individuals be equipped with a set of desirable abilities, competencies and skills to fulfill the above requirements. An interesting observation is that technical skills specific to a particular occupation though essential have not figured high on the list of desirable attributes.

The grumbles of employers about the quality of recruits have been longstanding, though the evidence on the issue is uneven. (Hesketh, 2000)Dissatisfaction expressed by employers over lack of desirable abilities in the recruits led countries around the globe to identify firstly the sets of attributes and skills required by the employers and secondly if they are included in the education system that prepares the students for work. The surveys and projects in the last decade made efforts to identify and define these non-specific occupational skills, which employers want in their recruits. So, now it is known that employability requires much more than occupation-specific qualifications.

In the recent past, there has been an evolution of workplaces and their requirements. There were days when willingness to work and academic qualifications were all that were required to make a start of a career. Nowadays, in contrast to the past, work is no longer routine, repetitive or organized along hierarchical lines but has become more problem-oriented, flexible and organized. Entry level workers now need to operate independently, use skills to solve problems and take decisions at work. There is a climate of worker collaboration and team work necessitating the worker to be creative, flexible, possessing interpersonal skills along with managerial skills. Research found that employers value generic skills that are transferable to situations over specific occupational skills. (Baxter and Young, 1982) It is also found that employers emphasize that educators should take most of the responsibility for equipping young people with general skills, which allow effective participation in the workplace.

Greater automation of the workplace has led to the concept of the "knowledge worker". There is also the globalization factor. Current economy is also coming to be known as the "Global Knowledge based Economy" where mental ability adds value to work. The knowledge worker adds value to his work by mental activities. So, in addition to technical abilities the effectiveness of the knowledge worker depends on skills like analyzing and solving problems. Economic success is being largely attributed to this knowledge and to the knowledge workers. The present economic environment has made the employers demand not only highly skilled workers but also workers with a wider range of skills. Also, they do not want this wide range of skills to be skewed to a limited few managerial positions, but to be distributed normally across the entire population of employees.

\section{UNPACKING EMPLOYABILITY SKILLS}

Although employability skills are embedded in most courses throughout life, students often fail to relate them to the employment context. The employability skills are holistic in nature. They are related not only to secure work but also contribute to the work once acquired and assist in the development throughout the career span of an individual. Hence, it is important to relate to these skills developed beyond the context of education and look forward to utilizing them during one's career.

Employability skills can be categorized into skills that are needed to start a job and skills needed to perform well in a job, remain in employment and progress through the career. So, there are threshold employability skills and sustainable employability skills. Sustainable employability skills are needed to be acquired by individuals already in work for furthering their professional development. A positive attitude and reliability are the two qualities that employers identify as most important when hiring someone for entry level work (Regenstein et al., 1998). However, certain skills, such as communication skills and team work are required at all levels of employment and are crucial to both threshold and sustainable levels of employability. When an employee progresses from entry level of employability, competence in job-specific skills as well as skills of learning and career management acquire increasing importance.

It can be said that employability is definitely not about just helping people to get a job and is also not about creating new qualifications. Employability skills are indicative of an ability to operate in ambiguous situations and also imply that capable person can work effectively on unfamiliar problems 
in unfamiliar contexts as well as on familiar problems in familiar contexts. It can be said that employability skills, attributes and aptitudes are generic, which means they are not discipline-specific, although they need a discipline where they can be demonstrated. They are also called transferable skills since they are able to be transferred over and across disciplines.

\section{EMPLOYABILITY SKILLS IN THE THRESHOLD OF 21ST CENTURY}

The world started taking interest in skills in the later half of $20^{\text {th }}$ century, which learned in one context could fairly and readily transferred to another context. This concept was defined by Bridges in 1993 as the generic capabilities. The study by the American Society for Training and Development (ASTD) and another by the Secretary's Commission on Achieving Necessary Skills (SCANS, 1991) are instrumental in identifying employability skills. ASTD emphasized 16 skill groups across all job families.

- Basic Competency Skills: reading, writing, computation

- Communication Skill: speaking, listening

- Adaptability Skills: problem-solving, creative thinking

- Developmental Skills: self-esteem, motivation, goal-setting, career planning

- Group Effectiveness Skills: interpersonal skills, teamwork, negotiation

- Influencing Skills: understanding organizational culture, sharing leadership

Mayer's committee set up in 1991 by the Australian Chamber of Commerce and Industry identified seven employment related key competencies: collecting; analyzing and organizing information; communicating ideas and information; planning and organizing activities; working with others and in teams; using mathematical ideas and techniques; solving problems; and using technology. These key competencies formed a firm foundation for the identification of skills required to successfully participate in the world of work.

Employers in an Australian study indicated that creativity and flair, independent and critical thinking, oral business communication skills and problem-solving capacity were the areas of generic skills with greatest perceived deficiencies. (Nelson, AC, 2000)

The Conference Board of Canada made a survey in Canada with a list of generic skills expected by employers before they hire new employees (who already possess the required technical skills). The Board called them the employability skills and has grouped them into three categories of foundation skills.

1. The fundamental skills are the skills needed as a base for further development.

2. The personal management skills are the personal skills, attitudes and behaviors that drive one's potential for growth.

3. The teamwork skills are the skills and attributes needed to contribute productively.

The range of requirements is reflected in employers' survey responses, with over90 per cent nominating that they look for people who are flexible and adaptive, willing to learn on the job, team workers, technically competent and committed to excellence (see figure). Good communication skills, commitment to the company and work experience also rate very highly. These 'soft' skills are even more important to firms when selecting trainee - two-thirds say that they look for technical skills in potential trainees and apprentices, but 100 per cent look for a positive attitude to work and willingness to learn and around 90 per cent look for communication skills and numeracy and literacy skills.

A comparison with results suggests that the importance of these skills is rising. Although high proportions of employers valued skills such as teamwork, the ability to learn and communication skills seven years ago, even higher proportions look for these skills in their employees and apprentices now. All of these attributes will remain important to employers in coming years.

\section{Wider PERSPECTIVES OF EMPLOYABILITY}

The Australian Government firmly believes that enhancement of employee skills is fundamental to strategies required for the growth and competitiveness in the industry. The ACCI included the key 
competencies such as team work and communication, problem-solving and technical skills, selfmanagement, learning, initiative and enterprise, also personal attributes like loyalty, integrity and a sense of humour. The ACCI, interestingly, does not support that personal traits to be taught or assessed, but advocate that they should be a part of an awareness raising activity only.

If students and their ability to respond to the changing needs of a rapidly developing labor market are viewed as valuable resources in the increasingly knowledge-based economy, we can think of employability as a product. But from a different perspective, employability can be considered a set of skills, knowledge and attributes required by all individuals for effective functioning at the workplace. Employability can be viewed to meet employer needs where in some employment contexts, the actual subject discipline may be relatively unimportant. Achievements outside the boundaries of the discipline are generally considered to be important in the recruitment of graduates. (Mantz, 2006)

The shift from the times when employers sought to train and retain their employees, whenever the industry was restructured or when new industries were stimulated, is an interesting factor. Now, the responsibility for all this is shifted to individuals, who need to "up-skill" and also change direction in the face of opportunity and requirement. However, the structures and patterns of change are such that they do not allow any scope for predicting what type of skills will be required. Workers, therefore, require attributes, attitudes, capacities not only to adapt but also to continuously upgrade themselves through generic skills that can be transferred with ease across different settings.

According to various surveys, employability skills are also known as social skills, life skills, basic skills, people skills, transferable skills, generic skills, core skills, key skills, soft skills, personal skills, interpersonal skills, behavior skills etc. There is still confusion over the terminology used to describe these generic skills but generally the employers surveyed by various researchers spoke of similar sets of skills when they used these terms.

\section{CONCLUSION}

Although there seems to be no common definition for the term "soft skills", there seems to be a general agreement that they are related to people-oriented skills and self-management skills. And that the same skills are also instrumental in improving the productivity of workforce and increasingly linked to the employability of individuals.

The enhancement of these skills in individuals aims to achieve a process of continuous development rather than a single static outcome. Creating lifelong employment capabilities in individuals is a role found to be played by the enhancement of soft skills. Additionally, these skills aim to equip an individual with the ability not only to select a vocation, but to acquire a job and then retain the job.

\section{REFERENCES}

[1] AC Nelson Research Services (2000), "Employer Satisfaction with Graduate Skills", Evaluation and Investigations Programme, Higher Education Division, Canberra, Department of Education, Training and Youth Affairs

[2] Australian Industry Group (2006), "World Class Skills for World Class Industries - Employer's perspectives on skilling in Australia", A Survey of Australian Employers 2005, the Allen Consulting Group, Melbourne

[3] Baxter M B and Young J L (1982), "What Do Employers Expect from High School Graduates?” , NASSP Bulletin, Vol. 66, No. 458

[4] Bridges D (1993), "Transferable Skills: A Philosophical Perspective”, Studies in Higher Education, Vol. 18, No. 1, pp. 43-51

[5] Hesketh A J (2000) "Recruiting an elite? Employers' perceptions of graduate education and training", Journal of Education and Work, Vol. 13, No. 3, pp. 245-271

[6] http://www.cit.act.edu.au/data/page/188/Employability_Skills.pdf

[7] http://www.le.ac.uk/ssds/esac/defining_employability.html

[8] http://www.saalt.com.au/cgea/about/module/general/modgco1.html

[9] http://www.shu.ac.uk/research/cre/Employabilitydefiningemployabilty.htm

[10] Mantz (2006), Employability in Higher Education: What it is-What it is Not?

[11] Regenstein Marsh, Jack A Meyer and Jennifer Dickemper Hicks (1998), "Job Prospects for Welfare Recipients: Employers Speak Out', July, Urban Institute, Washington DC 


\section{AUTHOR'S BIOGRAPHY}

Dr. B. Bala Nagendra Prasad, holds $\mathrm{PhD}$ in English Literature from JNTUA Anantapuramu. Currently, he is working as Head, Dept. Of HS at Annamacharya Institute of Technology and Sciences (Autonomous) Rajampet, AP, India.

Citation: Dr. B.Bala Nagendra Prasad. "Soft Skills for Enhancing Employability" International Journal of Managerial Studies and Research (IJMSR), vol 5, no. 11, 2017, pp. 17-21. doi: http://dx.doi.org/10.20431/ 2349-0349.0511003.

Copyright: (c) 2017 Authors. This is an open-access article distributed under the terms of the Creative Commons Attribution License, which permits unrestricted use, distribution, and reproduction in any medium, provided the original author and source are credited. 